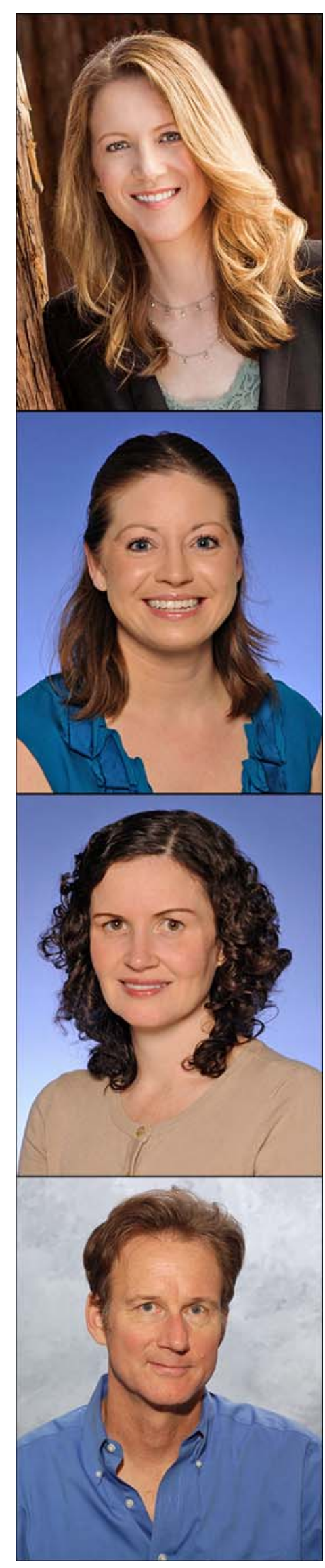

Shannon E. McCaslin, PhD; Bridget Leach, LCSW; Ellen Herbst, MD; Keith Armstrong, LCSW

\section{Overcoming barriers to care for returning Veterans: Expanding services to college campuses}

\section{INTRODUCTION}

The need to expand mental health and social work care available to Veterans in the community and for increased Department of Veterans Affairs (VA) and community partnership has become increasingly recognized [1]. Over 2.4 million men and women have served in Operation Iraqi Freedom (OIF), Operation Enduring Freedom (OEF), and/or Operation New Dawn (OND) since 2001 [2]. Following their deployments to combat zones and separation from the military, many Veterans are faced with the choice of obtaining employment, enrolling in college, or both. The Post-9/11 GI Bill, passed by Congress in 2008, greatly expanded educational benefits for Veterans who served in the Armed Forces on or after September 11, 2001 [3], and increasing numbers of former servicemembers are using this benefit. According to the Veterans Benefits Administration (VBA) Office of Educational Services, the number of Veteran students and beneficiaries (i.e., dependents or spouses) accessing VBA educational benefits across the United States has increased from 397,598 Veteran beneficiaries in 2000 to 564,487 in 2009 and to 1,014,227 in 2012, totaling over $\$ 10.5$ billion in utilized benefits (in 2011 alone) [4]. However, while the number of Veterans enrolled in college has dramatically increased, student Veterans have generally had lower graduation rates than their civilian counterparts [5]. Although the majority of student Veterans will complete their postsecondary programs, it has been estimated that about 30 to 40 percent will not [6], placing them at risk for adverse outcomes such as increased unemployment. This indicates a critical need to better understand and respond to the factors contributing to psychosocial difficulties among student Veterans that lead to poor academic outcomes. In this article, we will illustrate a replicable model that provides multifaceted Veterans Health Administration (VHA) healthcare, social work, and mental health services on the college campus and discuss ways in which clinicians and campus partners can promote wellness and academic success for student Veterans.

Veteran students arrive on campus with a military background that includes unique experiences, knowledge, skills, and codes of behavior. Factors that can influence adjustment from military service to student life include the amount of time between discharge and entry into college, differences between military and civilian culture, balance between academic and other life responsibilities, and psychological consequences of combat or other trauma exposure. Military culture, which emphasizes service, respect, camaraderie, structure, discipline, and order, can differ from that of civilian or traditional college student life [7]. While military life can bring its own challenges and stressors, there are also significant benefits, such as having stable housing and income, healthcare, and support from superiors and/or peers, as well as generally more consolidated, centrally located or familiar resources. Loss of one's social network and need to obtain one's own housing, healthcare, and source of income can compound an often challenging cultural transition from the military to the college campus. 
Less than 10 percent of U.S. citizens serve in the military [8], and many civilian students may lack an understanding of the servicemember's experience. This disconnect is compounded by the often nontraditional status of student Veterans, who are typically older and often need to balance family (including parenting responsibilities), work, and academic demands. Indeed, nearly half (49.4\%) of servicemembers and Veterans who have deployed to Iraq and Afghanistan are married [9]. In addition to general cultural or experiential differences, Veterans who have deployed to Iraq and Afghanistan are at higher risk for a number of adverse medical, psychiatric, and social outcomes. Milliken et al. reported exposure to deployment-related stressors in Reserve and Active Duty soldiers at rates of 69.6 percent and 66.5 percent, respectively [10]. Deployment-related stressors include not only exposure to life-threatening events but also witnessing death and dying [11] and often profound losses of comrades and fellow servicemembers [12].

An estimated 25 percent of returning OIF/OEF/OND Veterans have mental health diagnoses, including posttraumatic stress disorder (PTSD) [13], and many of these Veterans may also be diagnosed with cognitive disorders due to blast-related traumatic brain injury (TBI) [14]. Both of these conditions can impair concentration and memory, placing Veterans at higher risk for academic problems. Moreover, a recent study of 628 student Veterans found that almost half (46\%) reported thoughts of suicide and 20 percent of these reported having a plan for suicide [15]. Of the student Veterans surveyed, a significant number endorsed experiencing anxiety (35\%), depression (24\%), and PTSD symptoms (46\%). Student Veterans have also been found to engage in increased health risk behaviors; a recent survey of 8,651 students found that student Veterans endorsed more safety-, tobacco-, and alcohol-related risk behaviors than civilian students [16]. Recent epidemiologic data support the preventative value of access to care, reporting that male Veterans under 30 who access VHA healthcare services are less likely to complete suicide than Veterans who do not utilize VHA care [17]. Taken together, these findings suggest a strong need to ensure that student Veterans, particularly those deployed under OIF/OEF/OND, can easily access adequate mental health, medical, and social work services.

While mental health, medical, and social work services may potentially improve Veterans' overall functioning and achievement of their academic goals, there are significant barriers to receiving needed services. Veterans may be unaware that they are eligible for medical, mental health, and other services through the VHA and may also have dif- ficulty navigating the complex web of support services and resources provided across governmental (federal, state, county), private, and nonprofit agencies. Approximately 56 percent $(899,752)$ of all separated OIF/OEF/OND Veterans have used VA healthcare since October 1, 2001 [18]. In addition, it has been estimated that only about 50 percent of Veterans with mental health diagnoses will seek mental health care [19]. Recent studies indicate that treatment engagement and retention of returning Veterans in traditional models of mental health care have been difficult for a number of reasons, including stigma of mental illness and treatment, as well as logistical barriers to care such as navigating health and mental health systems, lack of time to attend an appointment during daytime hours, and transportation difficulties [20]. Attending traditional weekly therapy appointments at a location off-campus can be particularly difficult for student Veterans with full-time school and work schedules. Additionally, studies have shown that younger Veterans and OIF/OEF/OND Veterans diagnosed with PTSD are less likely to engage in specialty care at traditional VHA medical centers than non-OIF/OEF/OND Veterans [21-22]. In one study, increased distance from a VA facility and receiving the first mental health diagnosis from a clinic other than a mental health clinic (e.g., primary care or specialty clinic) were associated with not having received a recommended course of treatment for PTSD [21]. However, there was an increased likelihood of attending the recommended number of treatment sessions when care was primarily received at a VA community clinic versus a VA medical center. By providing services in a convenient location on campus, stigma may be reduced, barriers to care reduced, and the likelihood of seeking treatment increased. Hoge called for innovative approaches to overcome such barriers and emphasized the importance of collaborative care [19]. Outreach to and collaboration with college campuses provides an opportunity to support Veterans in multiple ways, including providing information about VHA and community services, enrolling Veterans in VA healthcare on-site, and connecting them to medical services and appointments, as well as providing direct mental health and social work services. Direct access to care onsite increases the likelihood that Veterans will seek services and may contribute to academic success as Veterans' overall well-being improves. In turn, success in college may lead to higher rates of employment, higher paying jobs, and reduced disability among Veterans. Indeed, the Bureau of Labor Statistics [23-24] reported Veterans with higher education had lower unemployment rates and higher median weekly earnings. 
The San Francisco VA Medical Center's (SFVAMC's) City College of San Francisco (CCSF) Veterans Outreach Program (VOP) is an innovative and replicable example of a program of treatment delivery on campus. The CCSF VOP provides VHA services on the college campus, including VHA healthcare enrollment, education about VA resources, mental health treatment, social work services, and connections to additional supports and services not located on campus (i.e., increasing accessibility to medical center services). In this article, we describe the implementation of the CCSF VOP to illustrate key considerations in the development of such a program and discuss concrete ways providers at VA, in the community, and on college campuses can reach out to and collaborate with college campuses to support returning combat Veterans.

\section{NEW MODEL OF CARE: VETERANS OUT- REACH PROGRAM AT CITY COLLEGE OF SAN FRANCISCO}

Since the implementation of the Post-9/11 GI Bill, CCSF has experienced exponential growth in its Veteran student body, from 200 Veterans in 2006 to over 1,200 Veterans in 2012, with the number of Veterans enrolled at CCSF projected to continue to increase rapidly, in parallel with national trends. The VOP began as a partnership between officials at the SFVAMC and CCSF.

Established in 2010, the concept behind the SFVAMC's VOP at CCSF is to provide a "one-stop shopping” experience at a convenient location on campus where Veterans can access information; enroll in VA healthcare on-site; and receive a comprehensive range of mental health services (including evidence-based psychotherapy, psychiatric evaluation, and medication management) and assistance in navigating VHA, college campus, and community services. The evidence-based individual and couples therapies provided on-site include cognitive behavioral therapy (CBT) for depression, CBT for insomnia (CBT-I), cognitive processing therapy for PTSD and prolonged exposure (PE) for PTSD, CBT for attention deficit hyperactivity disorder, and emotionally focused couples therapy. Educational presentations are provided through the program to Veterans, staff, and faculty at CCSF on a variety of subjects such as readjustment and postdeployment issues, transition to the academic setting, wellness and fitness, sleep improvement, relationship improvement, from stress to success, suicide prevention, TBI, service and companion animals, online resources that can be used personally and professionally, smoking cessation, and employment.

The program's convenient location on campus and the broad range of services provided aim to lessen previously cited barriers to seeking care. Outreach has been provided to over 1,058 Veterans on campus, and over 373 student Veterans have been enrolled in local VHA healthcare. Approximately 46 percent of the Veterans seen for healthcare-related services in the VOP have served in Iraq and Afghanistan. In contrast, of the approximately 6.2 million individuals seen in traditional VHA medical centers and clinics between October 1, 2010, and September 30, 2011, only 7 percent were OIF/ OEF/OND Veterans [25]. These numbers indicate that providing services at a convenient, destigmatized location on campus may dramatically increase the likelihood that OIF/OEF/OND Veterans will seek VA healthcarerelated services. Key pieces of creating such a program include institutional support and collaboration, compliance and high risk management considerations, and outreach to faculty and nearby campuses.

\section{Institutional Support and Collaboration}

Creating an effective program requires commitment and investment from both the medical center and the college. Our program received funding for staff positions through both the local VA medical center and the VHA Veterans Integration to Academic Leadership (VITAL) program. In 2011, the VHA Mental Health Services recognized a need to provide more services on college campuses and by March 2011, selected five VHA medical centers across the country to receive funding for one VITAL position. In June of 2012, Mental Health Services then expanded VITAL and selected 16 additional VA medical centers to fund at least one position at each site for a total of 21 medical centers, serving approximately 72 schools across the country. Each VITAL program varies in the number of schools it serves, driven by the number of student Veterans attending school. This effort is distinct from the VBA VetSuccess on Campus program, which provides outreach to 94 schools across the country and provides vocational rehabilitation counseling, among other services, on campus. Currently, VHA and VBA are working collaboratively on their outreach and service delivery to student Veterans on campus to provide seamless access to VA care, resources, and services on campus and in the community.

Our CCSF partners have welcomed the provision of VHA services on campus and have provided confidential 
office space and additional resources (e.g., office equipment, parking). Student Veterans are frequently balancing multiple roles at one time (e.g., student, employee, parent), and ease of access to services (e.g., convenient location) can be a key factor. Proximity of the program space to the location where other VA services are processed or provided (e.g., VBA GI Bill benefits, Veteran Academic Counselors, and/or VA Certifying Officials) provides an excellent opportunity for outreach as Veterans are coming to the office to find out about their educational benefits or waiting to meet with an academic advisor to develop their educational plans. In this context, an intervention such as asking a Veteran if he or she is enrolled in VHA healthcare can be a very nonthreatening way to inform Veterans of their healthcare benefits; assist with VHA enrollment; and schedule medical, social work, or mental health appointments. This proximity also provides an opportunity to inform student Veterans about other campus and community resources that support Veterans' academic success or other goals. Collaboration with campus academic readiness and support programs, such as campus Disabled Student Programs and Services (DSPS), tutoring services, library services, Veteran's academic counselors, VBA GI Bill certifying officials, and student Veteran groups can also foster academic success for Veterans.

\section{Privacy and Compliance}

Establishing a secure and confidential office for delivery of VHA services on campus requires a number of critical steps. These include developing a memorandum of understanding between VHA and the college, ensuring The Joint Commission and Health Insurance Portability Accountability Act compliance, designing and maintaining a confidential office space, and working with both VHA and college safety officials to ensure that safety and disaster plans meet federal, state, and county requirements.

Working outside of the medical center context requires attention to management of high-risk situations, including procedures for managing suicidal or homicidal ideation and intent. It is also beneficial to develop a behavioral emergency policy that is consistent with procedures at the VHA, but incorporates elements unique to work on the college campus (e.g., notifying campus police, outlining procedures for placing involuntary holds).

\section{Outreach to Faculty and Nearby Campuses}

VA providers can collaborate with campus faculty and staff to develop and implement strategies for creating a "Veteran-friendly" campus. These interactions may include communication with faculty and staff through formal avenues such as faculty presentations (on topics such as military culture and/or how to support student Veterans on campus), and through informal interactions such as meetings with faculty in specific departments who would like to better respond to Veteran needs on campus or consultation with individual professors as issues arise. Outreach can also be conducted through presentations to other nearby colleges and universities.

Within the VOP program, feedback is solicited from both campus staff and student Veterans on a regular basis. Additional metrics are also being assessed, including Veteran satisfaction with services and academic goals and retention rates in mental health care for Veterans who have engaged in treatment. Future program goals include expansion of the program, including increased outreach to surrounding colleges and universities, increased provision of training to college campus faculty and staff, and delivery of additional psychoeducational seminars and programs to Veterans.

\section{VETERANS SERVED: CASE EXAMPLES}

The following are composite case examples of student Veterans seen in our program. Identifying information has been altered to protect the confidentiality of the students.

\section{Case 1}

A young male Navy Veteran, Mr. W., who had served in OEF and OIF, was waiting to meet with a Veterans Academic Counselor at CCSF in the waiting room just outside the VOP. A VOP Clinical Social Worker provided outreach services to Mr. W., inquiring if he was enrolled in or interested in learning more about VHA healthcare. Mr. W. expressed interest and was invited to discuss healthcare options confidentially inside the VOP office. In the office, Mr. W. expressed interest in establishing care with a primary medical provider and reported that he was experiencing insomnia that interfered with his daily functioning. Upon being informed of various healthcare options, Mr. W. accepted a primary care appointment at the VA medical center and agreed to schedule a mental health appointment for treatment of insomnia at the CCSF VA office because of the convenience of seeing a provider on campus. Mr. W. was subsequently enrolled in VHA healthcare and provided with a primary care appointment at the medical center. He returned for a follow-up visit and received a comprehensive psychiatric interview and 
medication evaluation. A treatment plan was developed, which included treatment for his insomnia using CBT-I. Additional biopsychosocial stressors emerged during the course of therapy after Mr. W. lost his housing. Mr. W. was referred by VOP staff to the VAMC's Health Care for Homeless Veterans program and was provided with housing close to campus in a transitional housing program for Veterans with mental health issues. With adherence to CBT-I treatment principles and with his new living situation, Mr. W. reported that his symptoms of insomnia greatly improved. At the conclusion of the academic semester, Mr. W decided to move to a new city where he would have more psychosocial support. VOP staff connected him with the OIF/OEF Program Manager in the new location and provided Mr. W. with medical and mental health referrals to the local VA. Mr. W. was able to make a smooth transition to new providers at the local VA medical center and continues to attend college in his new location. Mr. W. consistently praised the quality and convenience of services provided through the CCSF VOP and SFVAMC. The complex biopsychosocial needs of this Veteran, who had previously been unaware of his eligibility for healthcare or other VHA benefits, were addressed by providing mental health services, advocacy, and case management on campus. The availability of VOP staff and resources on campus likely contributed to Mr. W.'s ability to meet his academic goal to remain in college during this difficult period.

\section{Case 2}

VOP staff provided outreach services to Mr. L., an Army Infantry Veteran who had served in both Iraq and Afghanistan. Mr. L. stated that he did not have healthcare coverage and agreed to enroll in VHA healthcare, but declined mental health treatment. Mr. L. returned to the CCSF VOP approximately 3 mo later expressing some ambivalence about mental health services, but agreed to a mental health evaluation. He was diagnosed with PTSD, but declined all mental health services, accepting only smoking cessation treatment. At various times, Mr. L. would drop into the VOP office, schedule an appointment to discuss possible treatments for PTSD, but subsequently not appear for the scheduled appointments. Several months after enrollment in smoking cessation, Mr. L. dropped into the VOP office expressing concern about his increased levels of irritability and anger. His irritability and feelings of anger had been exacerbated when he had felt crowded by another student during a group project, prompting him to leave the classroom abruptly. Mr. L. had never previously received any mental health services, but given his level of distress, he agreed to both individual therapy and a medication evaluation. VOP staff referred Mr. L. to the DSPS department at CCSF for accommodations related to problems with concentration, attention, and hyperarousal symptoms. Mr. L. began to regularly attend therapy and medication management appointments at the VOP. Mr. L. initially engaged in about 10 sessions of CBT-focused psychoeducation and therapy on reducing depressive symptoms and stabilizing PTSD symptoms. After that time, Mr. L. expressed a willingness to engage in more intensive trauma-focused work and completed a course of PE therapy, after which he endorsed a significant decrease in symptoms of PTSD and depression, as well as a significant reduction in alcohol consumption and aggressive behavior. After nearly 8 mo of receiving mental health services on campus, but never traveling to the local VA medical center, Mr. L. was willing to be referred for a primary care appointment to address his musculoskeletal pain. Mr. L. completed his academic coursework for the semester and later successfully transferred to a 4 yr university. By providing a range of mental health services on campus, the CCSF VOP allowed Mr. L. to repeatedly "test the waters" with mental health care until he felt comfortable enough to fully engage in recommended treatment.

\section{Case 3}

VOP staff provided comprehensive services for a recently hospitalized (for a suicide attempt) OIF Veteran, Ms. J., diagnosed with panic disorder and PTSD, who was attending CCSF. VOP staff provided psychotherapy, medication management, and case management needs. VOP staff collaborated with DSPS staff to ensure Ms. J. was given appropriate accommodations in her classes. She successfully completed her coursework at CCSF and was accepted to a graduate program. Ms. J. was incredibly grateful for the services we provided her. She conveyed that she would not have successfully engaged in this level of care if we were not located on campus.

\section{RECOMMENDATIONS: A CALL TO ACTION}

1. VA medical centers and Vet Centers (Veterans Readjustment Counseling Centers) are in a unique position to partner with colleges and universities to provide mental health and social work services on college campuses to OIF/OEF/OND Veterans, a group with relatively poor retention rates and high drop-out rates 
in traditional models of VA mental health care. Providing outreach and clinical services on campus allows the VHA to offer services at a crucial time for returning Veterans shortly after their deployment and separation from the military. Outreach programs have the potential to become the "face" of the VA, demonstrating the VA's ability to engage a younger student Veteran population and challenge reluctance Veterans may have about engaging in VA healthcare.

2. Bringing multidisciplinary outreach, social work, and mental health services to campuses enables VA providers to be in a unique position of providing early intervention and preventative services to Veterans in a location where they are more likely to be able to follow through with mental health care.

3. Providing outreach services on campus allows VHA to raise Veterans' awareness of healthcare services that they may not have realized they were eligible for. Given the mandate for health insurance with the implementation of the Affordable Care Act (see www.va.gov/health/aca/), it is crucial to inform eligible servicemembers of their VA health benefits.

\section{CONCLUSIONS}

There are tremendous advantages to providing mental health and social work services on college campuses. Through this preventative model of care, services can be offered early after military service, fostering behaviors that can improve health outcomes, promote overall well-being and academic success, and reduce disability. It is not always feasible or practical to implement a comprehensive outreach and mental health program similar to that described. While our program offers a combination of outreach, onsite enrollment, social work services, individual and couples evidence-based psychotherapies, and psychiatric medication management, there are other programs that differ in their provision of services. For example, other VHA VITAL-funded programs may offer primarily outreach at multiple campuses or may focus on peer support, college courses, or close collaboration with the Vet Centers.

Mental health providers both within VHA and in the community, as well as college faculty and staff, can promote student Veteran wellness and functioning. Avenues for outreach and collaboration with Veterans on campus include developing a Veterans Task Force, building faculty and peer mentoring programs, designing coursework that incorporates or addresses Veteran issues, and implementing new Veteran-specific programs on campus. Mental health professionals working in the community or in college settings can also use existing contacts and educational means (e.g., meetings with Veteran groups on campus, Web sites) to increase their understanding of military culture and the ways in which military culture may influence treatment-seeking behaviors and symptom presentation.

In recent years, resources have been developed to facilitate the support of student Veterans. The Student Veterans of America provides online materials to guide the process of making a college campus Veteranfriendly. These materials include a specific guide, "Creating a Veteran friendly campus: A guide for college and university administrators," which can also be referenced by local VHA and community providers in the development of such a student Veteran program. These resources and contact information can be found at www.studentVeterans.org/ [5]. An additional online resource is the Toolkit for Veteran Friendly Institutions developed by the American Council on Education (vetfriendlytoolkit.acenet.edu/Pages/default.aspx/ [26]). This toolkit provides information on student Veteran programs across the United States, as well as directs users to relevant tools and resources.

Two additional Web sites have been developed recently by VHA and the National Center for PTSD: (1) The VA Campus Toolkit (www.mentalhealth.va.gov/ studentVeteran/index.asp [27]) and (2) The Community Provider Toolkit (www.mentalhealth.va.gov/ communityproviders/ [28]). The VA Campus Toolkit provides information on how faculty and staff can support student Veterans and includes resources for presentations and training as well as online resources. The Community Provider Toolkit provides information on connecting with VHA, understanding the military experience, and mental health and wellness. Finally, the Center for Deployment Psychology, funded in part by the Department of Defense, provides additional information and trainings for clinicians working with military servicemembers (www.deploymentpsych.org/ [29]).

These are valuable resources to support the efforts of mental health professionals who would like to promote success among student Veterans. Our nation's Veterans have often made great sacrifices in serving our country. Through supporting student Veterans in their academic and life goals, we can do our part to help them succeed and to serve them. 


\section{ACKNOWLEDGMENTS}

We acknowledge and thank the student Veterans, the faculty, and the staff at CCSF who have supported our collaborative efforts to provide services to Veterans on campus. We thank Brandina Jersky, MFT; Gerard Choucroun, MSW; Isaac Shayesteh; Morris Karo; Diana Nicoll, MD, PhD, MPH; and other SFVAMC staff who have supported the CCSF VOP program. We also thank Khamkay Chitaphong, LCSW, director of VITAL, for his contributions to this article and Samuel Santos, the associate dean of students at CCSF, who has provided support for the VOP program on campus. The views expressed in this article are those of the authors and do not necessarily represent the position or policy of the VHA or the Department of Defense.

\section{Shannon E. McCaslin, PhD; ${ }^{1-3^{*}}$ Bridget Leach, LCSW; ${ }^{1}$ Ellen Herbst, MD; $;^{1-2}$ Keith Armstrong, LCSW ${ }^{1-2}$ ${ }^{1}$ Mental Health Service, SFVAMC, San Francisco, CA; ${ }^{2}$ Department of Psychiatry, University of California, San Francisco, CA; ${ }^{3}$ Dissemination and Training Division, National Center for PTSD, Menlo Park, CA \\ *Email: Shannon.McCaslin@ucsf.edu}

\section{REFERENCES}

1. Straits-Tröster KA, Brancu M, Goodale B, Pacelli S, Wilmer C, Simmons EM, Kudler H. Developing community capacity to treat post-deployment mental health problems: A public health initiative. Psychol Trauma. 2011; 3(3):283-91. http://dx.doi.org/10.1037/a0024645

2. Defense Manpower Data Center Profile of service members ever deployed, as of November 30, 2012. Source: Contingency Tracking System files. Washington (DC): Department of Defense; 2012.

3. Department of Veterans Affairs GI Bill [Internet]. Washington (DC): U.S. Department of Veterans Affairs; [cited 2011 Sep 20]. Available from: http://www.gibill.va.gov/

4. Veterans Benefits Administration. Annual benefits report, fiscal year 2011 [Internet]. Washington (DC): U.S. Department of Veterans Affairs; 2011 [cited 2013 Sept 10]. Available from: http://www.vba.va.gov/REPORTS/abr/ 2011 abr.pdf

5. Student Veterans of America [Internet]. Washington (DC): Student Veterans of America; 2013 [cited 2013 Sept 10]. Available from: http://www.studentVeterans.org/

6. Cate CA. Exploring student veterans' post-secondary completion rates with two national surveys [Internet]. Washington (DC): Student Veterans of America; 2013 [cited 2013 Sept 10]. Available from: http://library.constantcontact.com/download/get/file/1102247846799-456/ Research+Brief+2013-1.pdf

7. Coll JE, Weiss EL, Yarvis JS. No one leaves unchanged: Insights for civilian mental health care professionals into the military experience and culture. Soc Work Health Care. 2011;50(7):487-500. [PMID:21846250]

http://dx.doi.org/10.1080/00981389.2010.528727

8. Tavernise S. As fewer Americans serve, growing gap is found between civilians and military. New York Times. 2011 Nov 25:A22.

9. Defense Manpower Data Center. Profile of service members ever deployed as of March 31, 2011. Source: Contingency Tracking System files. Washington (DC): Department of Defense; 2012.

10. Milliken CS, Auchterlonie JL, Hoge CW. Longitudinal assessment of mental health problems among active and reserve component soldiers returning from the Iraq war. JAMA. 2007;298(18):2141-48. [PMID:18000197] http://dx.doi.org/10.1001/jama.298.18.2141

11. Hoge CW, Castro CA, Messer SC, McGurk D, Cotting DI, Koffman RL. Combat duty in Iraq and Afghanistan, mental health problems, and barriers to care. N Engl J Med. 2004;351(1):13-22. [PMID:15229303] http://dx.doi.org/10.1056/NEJMoa040603

12. Toblin RL, Riviere LA, Thomas JL, Adler AB, Kok BC, Hoge CW. Grief and physical health outcomes in U.S. soldiers returning from combat. J Affect Disord. 2012; 136(3):469-75. [PMID:22154707] http://dx.doi.org/10.1016/j.jad.2011.10.048

13. Seal KH, Bertenthal D, Miner CR, Sen S, Marmar C. Bringing the war back home: Mental health disorders among 103,788 US veterans returning from Iraq and Afghanistan seen at Department of Veterans Affairs facilities. Arch Intern Med. 2007;167(5):476-82. [PMID:17353495] http://dx.doi.org/10.1001/archinte.167.5.476

14. Hampton T. Traumatic brain injury a growing problem among troops serving in today's wars. JAMA. 2011; 306(5):477-79. [PMID:21813422] http://dx.doi.org/10.1001/jama.2011.1092

15. Rudd MD, Goudling J, Bryan CJ. Student veterans: A national survey exploring psychological symptoms and suicide risk. Prof Psychol Res Pr. 2011;42(5):354-60. http://dx.doi.org/10.1037/a0025164

16. Widome R, Laska MN, Gulden A, Fu SS, Lust K. Health risk behaviors of Afghanistan and Iraq war veterans attending college. Am J Health Promotion. 2011; 26(2):109-16. http://dx.doi.org/10.4278/ajhp.090826-QUAN-278

17. Katz IR, McCarthy JF, Ignacio RV, Kemp J. Suicide among veterans in 16 states, 2005 to 2008: Comparisons between utilizers and nonutilizers of Veterans Health Administration (VHA) services based on data from the National Death Index, the National Violent Death Reporting System, and 
VHA administrative records. Am J Public Health. 2012; 102(Suppl 1):S105-10. [PMID:22390582]

http://dx.doi.org/10.2105/AJPH.2011.300503

18. Department of Veterans Affairs. Analysis of VA health care utilization among Operation Enduring Freedom (OEF), Operation Iraqi Freedom (OIF), and Operation New Dawn (OND) veterans [Internet]. Washington (DC): Department of Veterans Affairs; 2013. Available from:

http://www.publichealth.va.gov/docs/epidemiology/ healthcare-utilization-report-fy2013-qtr1.pdf

19. Hoge CW. Interventions for war-related posttraumatic stress disorder: Meeting veterans where they are. JAMA. 2011;306(5):549-51. [PMID:21813436] http://dx.doi.org/10.1001/jama.2011.1096

20. Kim PY, Thomas JL, Wilk JE, Castro CA, Hoge CW. Stigma, barriers to care, and use of mental health services among active duty and National Guard soldiers after combat. Psychiatr Serv. 2010;61(6):582-88. [PMID:20513681] http://dx.doi.org/10.1176/appi.ps.61.6.582

21. Seal KH, Maguen S, Cohen B, Gima KS, Metzler TJ, Ren L, Bertenthal D, Marmar CR. VA mental health services utilization in Iraq and Afghanistan veterans in the first year of receiving new mental health diagnoses. J Trauma Stress. 2010;23(1):5-16. [PMID:20146392] http://dx.doi.org/10.1002/jts.20493

22. Lu MW, Duckart JP, O’Malley JP, Dobscha SK. Correlates of utilization of PTSD specialty treatment among recently diagnosed veterans at the VA. Psychiatr Serv. 2011;62(8): 943-49. [PMID:21807835] http://dx.doi.org/10.1176/appi.ps.62.8.943

23. Bureau of Labor Statistics. Employment situation of veterans-2011 [Internet]. Washington (DC): U.S. Department of Labor; 2011 [cited 2013 Sep 10]. Available from: http://www.bls.gov/news.release/pdf/vet.pdf

24. Bureau of Labor Statistics. Earnings and unemployment rates by education attainment [Internet]. Washington (DC): U.S. Department of Labor; 2012 [cited 2013 Sept 10]. Available from: http://www.bls.gov/emp/ep_chart_001.htm

25. Department of Veterans Affairs. Analysis of VA health care utilization among Operation Enduring Freedom
(OEF), Operation Iraqi Freedom (OIF), and Operation New Dawn (OND) veterans-Revised [Internet]. Washington (DC): U.S. Department of Veterans Affairs; 2012 [cited 2013 Sept 10]. Available from: http://www.publichealth.va.gov/docs/epidemiology/ healthcare-utilization-report-fy2012-qtr3.pdf

26. American Council on Education. Toolkit for veteran friendly institutions [Internet]. Washington (DC): American Council on Education; 2013 [cited 2013 Sept 10]. Available from: https://vetfriendlytoolkit.acenet.edu/ Pages/default.aspx

27. Department of Veterans Affairs. VA campus toolkit [Internet]. Washington (DC): U.S. Department of Veteran Affairs; 2012 [cited 2013 Sept 10]. Available from: http:// www.mentalhealth.va.gov/studentVeteran/index.asp

28. Department of Veterans Affairs. Community provider toolkit [Internet]. Washington (DC): U.S. Department of Veteran Affairs; 2013 [cited 2013 Sept 10]. Available from: http://www.mentalhealth.va.gov/communityproviders/

29. Center for Deployment Psychology [Internet]. Bethesda (MD): Center for Deployment Psychology; 2013 [cited 2013 Sept 10]. Available from: http://www.deploymentpsych.org/

This article and any supplementary material should be cited as follows:

McCaslin SE, Leach B, Herbst E, Armstrong K. Overcoming barriers to care for returning Veterans: Expanding services to college campuses. J Rehabil Res Dev. 2013;50(8):vii-xiv.

http://dx.doi.org/10.1682/JRRD.2013.09.0204

ResearcherID/ORCID: Shannon E. McCaslin, PhD: L3229-2013

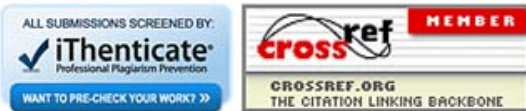

